\title{
BM] open The association of dental plaque with cancer mortality in Sweden. A longitudinal study
}

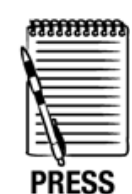

RELEASE

\author{
Birgitta Söder, ${ }^{1}$ Maha Yakob, ${ }^{1}$ Jukka H Meurman, ${ }^{2}$ Leif $\mathrm{C}$ Andersson, ${ }^{3}$ \\ Per-Östen Söder ${ }^{1}$
}

To cite: Söder B, Yakob M, Meurman JH, et al. The association of dental plaque with cancer mortality in Sweden. A longitudinal study. BMJ Open 2012;2:e001083. doi:10.1136/

bmjopen-2012-001083

- Prepublication history for this paper is available online. To view these files please visit the journal online (http:// dx.doi.org/10.1136/ bmjopen-2012-001083).

Received 1 March 2012 Accepted 19 April 2012

This final article is available for use under the terms of the Creative Commons Attribution Non-Commercial 2.0 Licence; see http://bmjopen.bmj.com

${ }^{1}$ Department of Dental Medicine, Karolinska Institutet, Huddinge, Sweden ${ }^{2}$ Department of Oral and Maxillofacial Diseases, Institute of Dentistry, University of Helsinki and Helsinki University Central Hospital, Helsinki, Finland ${ }^{3}$ Department of Pathology, Haartman Institute, University of Helsinki, Helsinki, Finland

Correspondence to Dr Birgitta Söder; birgitta.soder@ki.se

\section{ABSTRACT}

Objectives: To study whether the amount of dental plaque, which indicates poor oral hygiene and is potential source of oral infections, associates with premature death from cancer.

Design: Prospective cohort study.

Participants: 1390 randomly selected healthy young Swedes followed up from 1985 to 2009. All subjects underwent oral clinical examination and answered a questionnaire assessing background variables such as socioeconomic status and smoking.

Outcome measures: Causes of death were recorded from national statistics and classified according to the WHO International Classification of Diseases. Unpaired $t$ test, $\chi^{2}$ tests and multiple logistic regressions were used.

Results: Of the 1390 participants, $4.2 \%$ had died during the follow-up. Women had died at a mean age of $61.0( \pm 2.6 \mathrm{SD})$ years and men at the age of 60.2 $( \pm 2.9 \mathrm{SD})$ years. The amount of dental plaque between those who had died versus survived was statistically significant $(p<0.001)$. In multiple logistic regression analysis, dental plaque appeared to be a significant independent predictor associated with 1.79 times the $\mathrm{OR}$ of death $(\mathrm{p}<0.05)$. Age increased the risk with an $\mathrm{OR}$ of $1.98(\mathrm{p}<0.05)$ and gender (men) with an OR of $1.91(p<0.05)$. The malignancies were more widely scattered in men, while breast cancer was the most frequent cause of death in women.

Conclusions: This study hypothesis was confirmed by showing that poor oral hygiene, as reflected in the amount of dental plaque, was associated with increased cancer mortality.

\section{INTRODUCTION}

Dental plaque is a bacterial biofilm formed on dental surfaces. It plays a role in the aetiology of oral diseases such as caries and periodontal disease but may also associate with systemic health and diseases due to direct or hematogenic spread of microorganisms with subsequent upregulation of cytokines and inflammatory mediators. ${ }^{1}$ The dento-gingival region is a natural habitat for

\section{ARTICLE SUMMARY}

\section{Article focus}

- To study whether the amount of dental plaque, which indicates poor oral hygiene and a potential source of dental infections, is associated with with premature death from cancer.

\section{Key messages}

- Our study hypothesis was confirmed by the finding that poor oral hygiene, as reflected in the amount of dental plaque, was associated with increased cancer mortality.

Strengths and limitations of this study

- Our subjects were randomly chosen to avoid selection bias. The large subject pool was representative of the ethnically homogenous Swedish adult population, with an age range of 10 years to limit the influence of age differences.

- The present study reported an association between poor oral hygiene and increased cancer mortality; further studies are required to determine whether there is any causal element in the observed association.

a magnitude of oral bacteria. The average total microscopic count of bacteria from the dental plaque has been calculated to be up to $2.1 \times 10^{8} / \mathrm{mg}$ wet weight. ${ }^{2}{ }^{3}$ Paster $e t ~ a l^{4}$ estimated that there are 415 species of nonspecific bacteria in the subgingival plaque, while pyro-sequencing techniques analysing dental plaque and saliva have shown that even thousands of microbial species may inhabit the oral cavity. ${ }^{5}$

Carcinogenesis is a multi-step process in which cells accumulate changes in their genetic material giving rise to alterations of function. ${ }^{6}$ These metabolic cascades can also be triggered by infection and inflammation which, in fact, have been estimated to play a role in $15 \%-20 \%$ of all malignancies. ${ }^{7}$ Because oral infections, and periodontitis in particular, are highly prevalent in populations, there has been interest in studying 
the eventual link between oral infections and the prevalence of cancer. Smoking is a common risk factor both for periodontitis and in many types of malignancies; thus, smoking needs always to be taken into account in this context. ${ }^{8}$ Our group published a study in 2007 showing that patients with periodontitis and missing molars seem to be at increased risk for premature death by life-threatening diseases, such as neoplasms and diseases of the circulatory and digestive systems. ${ }^{9}$

We have recently also published a study showing an association between periodontal disease and breast cancer, with an OR of $2.36 .{ }^{10}$ The putative mechanisms involved in the association have been further reviewed by Meurman and Bascones-Martinez. ${ }^{11}$ Considering these observations, the hypothesis of the present study was that dental plaque is associated with premature death in cancer. A high amount of dental plaque indicates poor oral hygiene and, subsequently, was thought to be a surrogate for increased risk for dental infections. These, in turn, by triggering systemic reactions were thought to lead to malignant transformation in a variety of tissues. The specific aim of this study was to investigate the underlying causes of death in malignancies among 1390 randomly selected young Swedes who had been clinically investigated and followed up from 1985 to 2009. The Swedish national hospital admission and death registers were used to record cancer. Death from cancer was considered the end point of the study.

\section{MATERIALS AND METHODS}

\section{Study population}

In 1985, we undertook a study comprising a random sample of 3273 individuals aged 30-40 years. The subjects were selected from a registry file of all inhabitants of Stockholm County born on the 20th of any month from 1945 to $1954 \quad(n=105798)$. They were informed about the purpose of the study and offered a clinical oral examination. In total, 1676 individuals $(51.2 \%), 838$ men and 838 women, underwent the examination and answered a questionnaire. Of them, 286 had periodontal disease, while 1390 had no signs of periodontitis and were regarded as periodontally healthy. These 1390 subjects were then included in the present study. The study profile is given in figure 1 .

The following oral health parameters were recorded for the 1390 individuals with no periodontal disease: the number of remaining teeth excluding third molars, gingival inflammation around every tooth using the gingival index ${ }^{12}$ and oral hygiene status using the plaque index (PLI) ${ }^{13}$ and the calculus index ${ }^{14}$ to assess all six surfaces of six representative teeth. Gingival crevices were measured using a periodontal probe and recorded to the nearest higher millimetre for six sites of each tooth. Presence or absence of each tooth was recorded. All subjects answered a questionnaire concerning topics such as regular dental visits and the use of tobacco. Smoking was expressed in pack-years of smoking in the analyses.
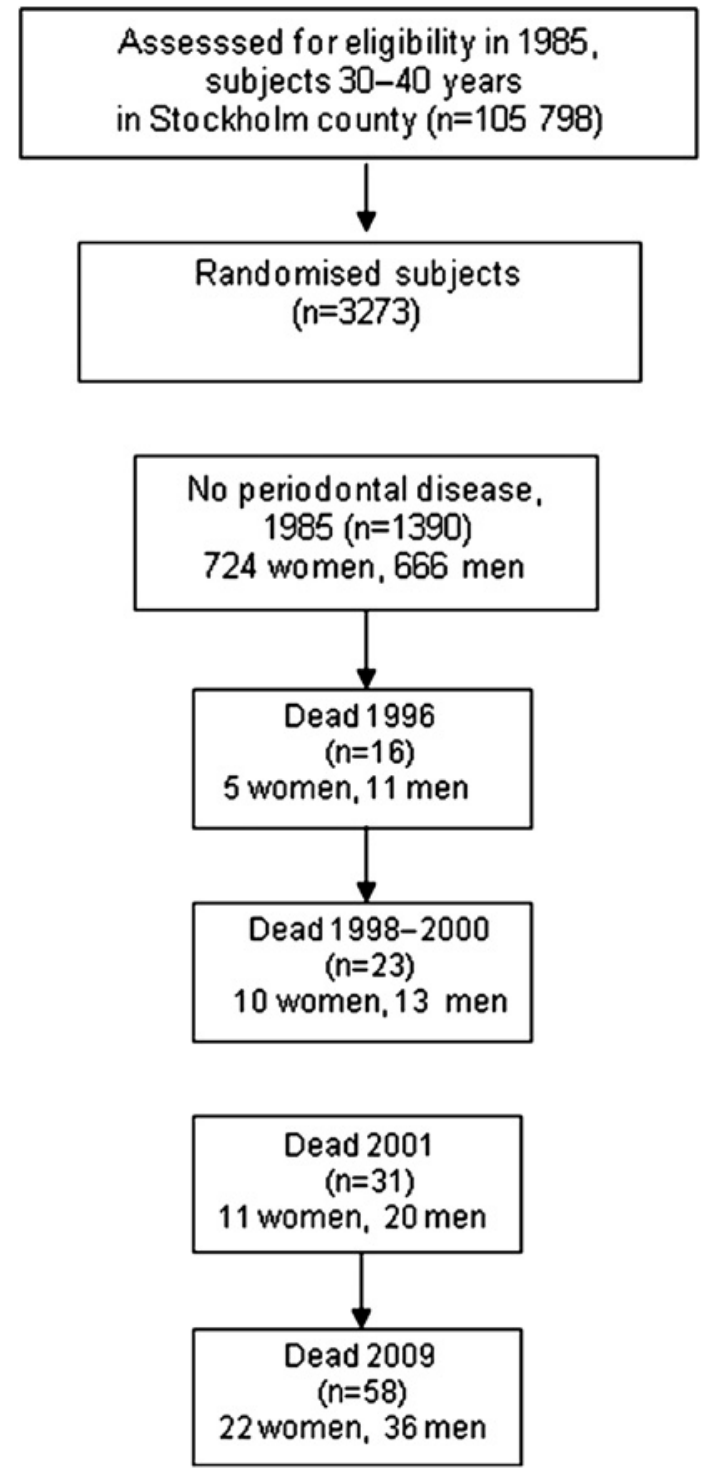

Figure 1 Study profile.

\section{Socioeconomic and mortality data}

The cumulated causes of death in the 1390 subjects followed up from 1985 to 2009 were obtained from the Centre of Epidemiology, Swedish National Board of Health and Welfare, Sweden. ${ }^{15}$ The data regarding the causes of death were classified according to the WHO International Statistical Classification of Diseases and Related Health Problems (ICD), ICD-7, ICD-9 and ICD10 , respectively. Socioeconomic data were obtained from the National Statistics Centre, Örebro, Sweden.

The Ethics Committee of the Karolinska Institute and Huddinge University Hospital, Sweden, had approved the study protocol (permit 2007/1669-31). The study is in accordance with the Declaration of Helsinki as revised in 1983.

\section{Statistical analysis}

Unpaired t test, $\chi^{2}$ tests, multiple regression analysis and multiple logistic regression analysis were applied when appropriate. We used multiple logistic regression 
Table 1 Demographic and clinical oral health data at the 1985 baseline examination of the 1390 subjects who were dead or alive by the follow-up year of 2009

\begin{tabular}{|c|c|c|c|}
\hline & $\begin{array}{l}\text { Dead }(n=58) \\
\text { Number, mean } \pm S D\end{array}$ & $\begin{array}{l}\text { Alive }(n=1332) \\
\text { Number, mean } \pm S D\end{array}$ & p Value* \\
\hline Gender (female/male) & 22/36 & $691 / 641$ & $<0.05$ \\
\hline Age in 1985 (years) & $36.5 \pm 2.9$ & $35.5 \pm 2.8$ & $<0.05$ \\
\hline Education (compulsary school/higher) & $14 / 44$ & $221 / 1111$ & $<0.001$ \\
\hline Smoking (pack-year) & $3090.7 \pm 3170.5$ & $2113.0 \pm 2901.5$ & $<0.05$ \\
\hline Income (Swedish Crowns $\times 1000)$ & $200.5 \pm 126.1$ & $180.0 \pm 99.7$ & NS \\
\hline Plaque index & $0.87 \pm 0.62$ & $0.67 \pm 0.46$ & $<0.001$ \\
\hline Gingival inflammation & $1.41 \pm 0.56$ & $1.17 \pm 0.46$ & $<0.001$ \\
\hline Calculus index & $0.57 \pm 0.68$ & $0.38 \pm 0.51$ & 0.008 \\
\hline Missing teeth & $1.64 \pm 2.90$ & $1.17 \pm 2.34$ & NS \\
\hline Missing molars in the mandible & $0.74 \pm 1.34$ & $0.47 \pm 1.17$ & NS \\
\hline
\end{tabular}

Data are expressed as mean \pm SD.

*Fisher's exact t test or Student's t test for unpaired samples as appropriate.

analysis to compare the incidence of total mortality according to the state of oral health at baseline, while simultaneously controlling for several potential confounding variables. We included in the model the variables of age, sex, education, income, socioeconomic status, smoking, dental visits and hospitalisation. The outcome variables were deaths from cancer. Differences between data sets with a probability of $<0.05$ were regarded as significant. All $\mathrm{p}$ values are two tailed, and CIs were calculated at the $95 \%$ level. All statistical analyses were performed using the PASW ${ }^{\circledR}$ Statistics software package, version 20 (PASW Inc., Chicago, Illinois, USA).

\section{RESULTS}

By the follow-up year of 2009, of the 1390 persons originally examined, 58 subjects had passed away, $35.6 \%$ of them were women and $64.4 \%$ were men. The difference between genders was statistically significant $(p=0.01)$. Of the total of the 3273 participants in the original cohort, $6.21 \%$ had died: $2.3 \%$ of the women and $3.9 \%$ of the men $(p<0.001)$. Approximately $6.9 \%$ of the women and $4.0 \%$ of the men had died from different cancers by the year $2009(\mathrm{p}<0.05)$. The women died at the average age of $61.0( \pm 2.67 \mathrm{SD})$ years and men at the average age of $60.2( \pm 2.96 \mathrm{SD})$ years. The difference between genders was not statistically significant.

Demographic data and risk indicators at the baseline examination in 1985 are given in table 1 . As mentioned previously, significantly more women than men were alive at the end of the study. The relative number of individuals with higher education was greater in the survivors, whereas higher pack-years of smoking characterised the persons who had passed away.

Statistically significant differences were evident between the groups regarding the amount of dental plaque, gingival inflammation and dental calculus, indicating a significantly poorer dental status in the subjects who died when compared with the survivors. The amount of dental plaque at the baseline examination in 1985, in subjects who were dead or alive in 2009 , is given in table 2. Those who had died by the year 2009 had PLI values from 0.84 to 0.87 (as recorded in 1985), indicating that the gingival region of the teeth had been covered with dental plaque. Those who survived had, respectively, in 1985, had constantly lower mean values of dental plaque (PLI 0.66). Thus, their gingival region had been only partly covered with plaque. The differences between the groups increased significantly also when comparing the 1985 clinical recordings from 1996 to 2009 , as also given in table 2 .

In the multiple logistic regression analysis, age, male gender and the amount of dental plaque appeared to be the principal independent predictors for death during the follow-up as given in table 3. Dental plaque associated with 1.79 times the odds of premature death. Except for age, which associated 1.98 times the odds for

Table 2 Dental plaque index (PLI), at baseline examination in 1985 for the 1390 subjects who were alive and dead from 1996 to 2009

\begin{tabular}{llllll}
\hline & Alive $(\mathbf{n})$ & Dead $(\mathbf{n})$ & PLI alive & PLI dead & p Value \\
\hline 1996 & 1371 & 16 & $0.67 \pm(0.47$ SD) & $0.84 \pm(0.58$ SD) \\
1998 & 1364 & 23 & $0.66 \pm(0.47$ SD) & $0.87 \pm(0.54$ SD) \\
2000 & 1367 & 23 & $0.66 \pm(0.46$ SD) & $0.87 \pm(0.54$ SD) \\
2001 & 1359 & 31 & $0.66 \pm(0.47$ SD) & $0.91 \pm(0.54$ SD) & $<0.05$ \\
2009 & 1332 & 58 & $0.66 \pm(0.46$ SD) & $0.87 \pm(0.62$ SD) & 0.001 \\
\hline
\end{tabular}


Table 3 The results of multiple logistic regression analysis of the relationship between death as a dependent variable and several independent variables (age, gender, dental visits, dental plaque, calculus, education, income, socioeconomic status, pack-years of smoking)

\begin{tabular}{llllll}
\hline Dependent variable & Explaining variable & $\boldsymbol{\beta}$ & $\boldsymbol{\chi}^{\mathbf{2}}$ & $\mathbf{p ~ V a l u e}$ & OR (95\% CI) \\
\hline Death & Age & 0.68 & 5.27 & 0.022 & $1.98(1.11$ to 3.54$)$ \\
& Gender (male) & 0.65 & 4.50 & 0.034 & $1.91(1.05$ to 3.46$)$ \\
& Dental plaque & 0.58 & 3.90 & 0.048 & $1.79(1.01$ to 3.19) \\
\hline Cox \& Snell $R^{2}=0.017$; Nagelkerke $\mathrm{R}^{2}=0.060$. & & &
\end{tabular}

death, and male gender (OR 1.91), the other factors considered in the model exerted no significant independent influence on these three variables.

The causes of death due to malignancies are given in detail in table 4. In the women, malignant neoplasm of the breast was the most frequent cause of death. In men, the diagnoses of malignancies were more widely scattered. In three cases, two women and one man, no cause or underlying cause of death could be found in the register file.

\section{DISCUSSION}

This study addressed the issue of dental plaque as a risk marker for mortality by evaluating the relationship between the clinically recorded amount of dental plaque and death due to malignancies 24 years after the baseline dental examination. Our results confirmed the study hypothesis by showing that the amount of dental plaque indeed associated with death in cancer, similar to what was observed with age and male gender. The deceased women in the study cohort were expected to live 13.1 years longer and the deceased men 8.6 years longer, according to population demographics in Sweden. ${ }^{16}$ Hence, the deaths recorded here could be termed 'premature deaths'.

Regarding the reliability of the results, our subjects were randomly chosen to avoid selection bias. The large subject pool was representative of the ethnically homogenous Swedish adult population, with an age range of 10 years to limit the influence of age differences. The study had a longitudinal prospective design with a cohort of subjects whose oral health status was documented at the baseline 24 years earlier. The statistical analysis was performed with adjustments for several demographic variables and established risk markers for mortality, such as education, pack-years of smoking, frequency of dental visits, income level, socioeconomic status, gingival inflammation and periodontal disease. Therefore, none of these variables confounded the association observed between the age, male gender, the amount of dental plaque and premature death.

The subjects who had died by the year 2009 had been healthy in the 1985 examination, with no signs of periodontal or other oral disease; however, a voluminous oral biofilm had been covering the gingival crevice

Table 4 The causes of death

\begin{tabular}{|c|c|c|}
\hline ICD-10 & Men (n) & Women (n) \\
\hline Malignant neoplasm of oesophagus, abdominal part of oesophagus (C15.2) & 1 & \\
\hline Malignant neoplasm of colon, sigmoid colon (C18.7) & & 1 \\
\hline Malignant neoplasm of rectum, rectal ampulla (C20) & 1 & \\
\hline Malignant neoplasm of pancreas, unspecified (C25.9) & & 2 \\
\hline Malignant neoplasm of bronchus and lung, upper lobe, bronchus or lung (C34.1) & 1 & \\
\hline Malignant neoplasm of bronchus and lung, unspecified (С34.9) & 1 & \\
\hline Malignant melanoma of trunk (C43.5) & 2 & \\
\hline Malignant melanoma of lower limb, including hip (C43.7) & & 1 \\
\hline Malignant neoplasm of skin, skin of lower limb, including hip (C44.7) & 1 & \\
\hline Malignant neoplasm of connective and soft tissue of lower limb, including hip (C49.2) & 1 & \\
\hline Malignant neoplasm of breast, upper-outer quadrant of breast (C50.4) & & 4 \\
\hline Malignant neoplasm of breast, unspecified (C50.9) & & 8 \\
\hline Malignant neoplasm of cervix uteri (C53.9) & & 1 \\
\hline Malignant neoplasm of corpus uteri, endormetrium (C54.1) & & 1 \\
\hline Malignant neoplasm of prostate (C61.9) & 2 & \\
\hline Malignant neoplasm of bladdder, unspecified (C67.9) & 1 & 1 \\
\hline Malignant neoplasm of eye (C69.9) & & 1 \\
\hline Malignant neoplasm of meninges, cerebral meninges (C70.0) & 1 & \\
\hline Malignant neoplasm of brain, temporal lobe (C71.2) & 1 & \\
\hline Malignant neoplasm, parathyroid gland (C75.0) & 1 & \\
\hline Malignant neoplasm, pituitary gland (C75.1) & & 1 \\
\hline
\end{tabular}


(table 2). According to Socransky and Haffajee ${ }^{3}$, in healthy individuals, even with no signs of periodontal disease, the microbial plaque may still contain $33 \times 10^{8}$ cells. A healthy oral cavity harbours a characteristic bacterial flora that differs from that observed in oral disease states. ${ }^{17}$ The tooth surfaces are in contrast to the epithelial surfaces of the mouth not self-cleaning and that is the reason why dental plaque (oral biofilm) must be regularly removed by cleaning the teeth. If maintaining daily oral hygiene is neglected, microbial deposits accumulate. Consequently, microbial cells, toxins and enzymes are released from the biofilm and through the epithelium, particularly in the gingival crevice; the microbes and their metabolites may enter the blood circulation and spread to different parts of the body with potential systemic consequences.

In the year 2009, there were altogether 54611 cases of cancer diagnosed and reported to the Swedish Cancer Registry (the gender distribution was 53\% men and 47\% women).${ }^{15}$ During the last 2 decades, the average annual increase in the number of cases with malignancies has been $1.9 \%$ for men and $1.3 \%$ for women. ${ }^{15}$ These figures can be compared with those in the present cohort, where altogether 203 subjects had died from cancer: $6.9 \%$ women and $4.0 \%$ men. The increase in cancer cases can be partly explained by the ageing population and by the introduction of screening activities and improvements in diagnostic practices.

Breast cancer is the most common cancer in women in Sweden. It represented $29 \%$ of the cases reported to the Swedish National Cancer Registry in the year 2009. Breast cancer was the most common cancer causing death in women in the present study also, representing $21.4 \%$ (table 4). In men, in turn, the most frequent cancer in Europe is prostate cancer, with increasing incidence over the past 2 decades. The incidence of prostate cancer appears particularly high in Sweden, Finland and in The Netherlands. ${ }^{18}$ In Sweden, prostate cancer represented $36 \%$ of the male cases in 2009 in the national registry. In general, the increase in prostate cancer prevalence is related to the use of prostatespecific antigen in diagnosis, and therefore, it is uncertain how the incidence trend will develop over the coming years. In the present study, $3.6 \%$ of the men had died in prostate cancer.

In conclusion, based on the present findings, the high bacterial load on tooth surfaces and in gingival pockets over a prolonged time may indeed play a role in carcinogenesis. Therefore, the control of oral biofilm, in order to reduce the burden of the microbial noxa from the mouth, seems important to combat this development. Further studies are definitely required, however, to determine whether there is any causal element in the observed association reported here. If proven to be so, then new strategies for prevention and practical health recommendations would be warranted.

Contributors All authors fulfil all three of the ICMJE guidelines for authorship that are (1) substantial contributions to conception and design, acquisition of data or analysis and interpretation of data; (2) drafting the article or revising it critically for important intellectual content and (3) final approval of the version to be published. Dr BS is the corresponding author. She had full access to all data in the study and had final decision to submit the manuscript for publication.

Funding This study was supported by Ministry of Health and Social Affairs (grants F84/189) and Karolinska Institutet, Stockholm, Sweden, The Finnish Medical Society, Helsinki, and by grant TI020Y0003 by the Helsinki University Central Hospital, Finland.

\section{Competing interests None.}

Patient consent Obtained.

Ethics approval Ethics approval was provided by the Ethics Committee of the Karolinska Institute and Huddinge University Hospital, Sweden, had approved the study protocol (permit 2007/1669-31). The study is in accordance with the Declaration of Helsinki as revised in 1983.

Provenance and peer review Not commissioned; externally peer reviewed

Data sharing statement No unpublihed data are available.

\section{REFERENCES}

1. Bascones-Martínez A, Muñoz-Corcuera M, Meurman JH. Odontogenic infections in the etiology of infective endocarditis. Cardiovasc Hematol Disord Drug Targets 2009;9:231-5.

2. Socransky SS, Gibbons RJ, Sawyer S, et al. The microbiota of the gingival crevice area of man. II. The predominant cultivable organisms. Arch Oral Biol 1963;8:281-9.

3. Socransky SS, Haffajee AD. Periodontal microbial ecology. Periodontol 2000 2005;38:135-87.

4. Paster BJ, Boches SK. Bacterial diversity in human subgingival plaque. J Bacteriol 2001;183:3770-83.

5. Keijser BJ, Zaura E, Huse SM, et al. Pyrosequencing analysis of the oral microflora of healthy adults. J Dent Res 2008;87:1016-20.

6. Chang $\mathrm{AH}$, Parsonnet J. Role of bacteria in oncogenesis. Clin Microbiol Rev 2010;23:837-57.

7. Allavena P, Garlanda C, Borrello MG, et al. Pathways connecting inflammation and cancer. Curr Opin Genet Dev 2008;18:3-10.

8. Warnakulasuriya S. Living with oral cancer: epidemiology with particular reference to prevalence and life-style changes that influence survival. Oral Oncol 2010;46:407-10.

9. Söder B, Jin LJ, Klinge B, et al. Periodontitis and premature death: a 16 -year longitudinal study in a Swedish urban population. $J$ Periodontal Res 2007;42:361-6.

10. Soder B, Yakob M, Meurman JH, et al. Periodontal disease may associate with breast cancer. Breast Cancer Res Treat 2011;127:497-502.

11. Meurman JH, Bascones-Martinez A. Are oral and dental diseases linked to cancer? Oral Dis 2011;17:779-84.

12. Loe $H$, Theilade $E$, Jensen $B$. Experimental gingivitis in man. $J$ Periodontol 1965;36:177-87.

13. Silness J, Loe H. Periodontal disease in Pregnancy. II. Correlation between oral hygiene and periodontal condtion. Acta Odontol Scand 1964;22:121-35.

14. Greene JC, Vermillion JG. The oral hygiene index: a method for classifying oral hygiene status. J Am Dent Assoc 1960;61:172-9.

15. Cancer Incidence in Sweden 2009. Vol. 52. Stockholm, Sweden: Swedish Cancer Registry, 2010:2-104.

16. Life Expectancy 1861-2009. Statistical Year-Book of Stockholm 2011 Vol. 104. Stockholm: Stockholm Office of Research and Statistics (USK).

17. Aas JA, Paster BJ, Stokes LN, et al. Defining the normal bacterial flora of the oral cavity. J Clin Microbiol 2005;43:5721-32.

18. Bray F, Lortet-Tieulent J, Ferlay J, et al. Prostate cancer incidence and mortality trends in 37 European countries: an overview. Eur $J$ Cancer 2008;46:3040-52. 